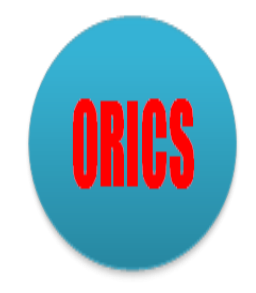

Available online at http://iorajournal.org/indx.php/orics

Operations Research: International Conference Series

Vol. 1, No. 1, pp. 13-18, 2020

\title{
Value-at-Risk Estimation Method Based on Normal Distribution, Logistics Distribution and Historical Simulation
}

\author{
Dwi Susanti $^{\mathrm{a} *}$, Sukono $^{\mathrm{a}}$, Maria Jatu Verrany ${ }^{\mathrm{a}}$ \\ ${ }^{a}$ Department of Mathematics, Faculty of Mathematics and Natural Sciences, Universitas Padjadjaran, \\ Jl. Raya Bandung Sumedang KM.21, Hegarmanah, Kec. Jatinangor, Kabupaten Sumedang, Jawa Barat 45363, Indonesia \\ *corresponding author: dwi_susanti65@yahoo.com
}

\begin{abstract}
This paper discusses the risk analysis of single stock and portfolio returns. The stock data analyzed are BNI, BRI shares and portfolio. After obtaining a stock return, value at risk $(\mathrm{VaR})$ will be estimated using the normal distribution approach, logistic distribution, and historical simulation. From the VaR results, a backtest is then conducted to test the validity of the model and the backtest results for BNI and the portfolio produce a smaller QPS on the historical simulation method compared to the normal distribution and logistics distribution approaches. This shows that BNI VaR and VaR portfolios with the historical simulation method are more consistent than other methods. While the backtest results for BRI produced the smallest QPS on the normal distribution approach compared to the logistical distribution and historical simulation approaches. This shows that the VaR BRI using the normal distribution approach is more consistent than the other methods.
\end{abstract}

Keywords: Value at Risk, backtest, normal distribution, logistics distribution, historical simulation.

\section{Introduction}

Every company, especially those engaged in finance or financial institutions are very vulnerable to risk, and financial activity is also very unstable. In the financial world, if there is a crisis that destroys the economic sector so that it can result in losses, then one of the losers is an investor. So investors should be able to face all the risks that might occur in order to obtain the results as expected and also be able to calculate these risks properly in order to avoid losses (Redhead, 1997; Husnan, 1994).

Therefore, a risk measurement method is needed that is able to translate these risks in a quantitative form so that they can be widely used and serve as an early warning in the financial sector that can be dealt with immediately (Dowd, 2002). Quantitative risk measurement can use Value at Risk (commonly abbreviated as $\mathrm{VaR}$ ) which has been widely used in finance and has become a general standard in risk calculation because it can be applied to all types of risk (Marrison, 2002). 
The purpose of this paper is to estimate VaR using the normal distribution approach, logistic distribution, and historical simulation methods. Of the three methods will be tested for validity called backtest and compare which method is best for estimating VaR.

\section{Methodology}

\subsection{Single and Portfolio Investment Returns}

For example the stock price for $k$ shares on the $i$ and $i-1$ days is equal to $P_{i}$ and $P_{i-1}$. So that in the time horizon of 1 day ( 24 hours), the return obtained on the $i$-day is

$$
r_{k i}=\ln \left(\frac{P_{i}}{P_{i-1}}\right) \text {. }
$$

The calculation of portfolio returns on day $i$ which is denoted by $r_{p i}$ with $N$ number of shares is

$$
r_{p i}=\sum_{k=1}^{N} \omega_{k} r_{k i} \text {. }
$$

where $\omega_{k}$ is the weight of stock $k$ with the total number of shares formed must be 1 and $r_{k i}$ is the stock return $k$ at time $i$ (Ruppert, 2004).

\subsection{Distribution and parameters}

\subsubsection{Normal distribution and parameters}

The general form of a normal distribution model is as follows. Refer to Dudewicz and Mishra (1988) $\&$ Walpole and Myers (1978), the random variable $X$ which has a mean $\mu$ and variance $\sigma^{2}<\infty$ is said to be normally distributed, if the probability density function is

$$
f(x)=\frac{1}{\sigma \sqrt{2 \pi}} e^{-\frac{1}{2}\left(\frac{x-\mu}{\sigma}\right)^{2}},-\infty<x<\infty .
$$

Following is the estimated mean $\hat{\mu}$ and the variance $\hat{\sigma}^{2}$ :

$$
\hat{\mu}=\frac{1}{n-1} \sum_{i=1}^{n} x_{i} \text { and } \hat{\sigma}^{2}=\frac{1}{n-1} \sum_{i=1}^{n}\left(x_{i}-\mu\right)^{2} .
$$

\subsubsection{Logistics Distribution and Estimated Parameters}

Bassed on Hogg and Craig (1995) \& Mood et al. (1963), the logistics distribution has a symmetrical continuous probability density function and has two parameters, namely location $\mu$ and scale $\sigma$. The probablility density function is

$$
f(x)=\frac{e^{-\left(\frac{x-\mu}{\sigma}\right)}}{\sigma\left(1+e^{-\left(\frac{x-\mu}{\sigma}\right)}\right)^{2}}, \quad-\infty<x<\infty .
$$

Following is the estimated mean $\hat{\mu}$ and the variance $\hat{\sigma}^{2}$ :

$$
\hat{\mu}=\mu=\frac{1}{n-1} \sum_{i=1}^{n} x_{i} \text { and } \hat{\sigma}^{2}=\frac{\pi^{2}}{3} \sigma^{2}=\frac{\pi}{3(n-1)} \sum_{i=1}^{n}\left(x_{i}-\mu\right)^{2} \text {. }
$$




\subsection{VaR Estimation with the Normal Distribution Approach Method}

VaR estimation with the normal distribution approach is a parametric estimation of VaR assuming that returns are normally distributed and $\mathrm{VaR}$ is estimated using parameters such as mean and variance (Ruppert, 2004: 348).

VaR estimation for stock $k$ (single investment) with confidence coefficient $(1-\alpha) 100 \%$ is

$$
\operatorname{VaR}_{k}(\alpha)=-S_{0}\left(\hat{\mu}_{k}+\Phi^{-1}(\alpha) \hat{\sigma}_{k}\right)
$$

where $S_{0}$ is the initial investment, $\hat{\mu}_{k}$ and $\hat{\sigma}_{k}$ are the mean and standard deviations of stock return $k$, respectively, and $\Phi^{-1}(\alpha)$ shows the inverse of the normal standard value $Z$ which can be seen in the normal distribution table.

$\mathrm{VaR}$ estimation for portfolio investment is

$$
\operatorname{VaR}_{p}(\alpha)=-S_{0}\left(\hat{\mu}_{p}+\Phi^{-1}(\alpha) \hat{\sigma}_{p}\right)
$$

where $S_{0}$ is the initial investment, $\hat{\mu}_{p}$ and $\hat{\sigma}_{p}$ are the mean and standard deviations of portfolio, respectively.

\subsection{VaR Estimation with the Logistics Distribution Approach Method}

VaR estimation using logistic distribution approach is parametric estimation VaR. In this case, the return is assumed to be logistically distributed.

VaR estimation for stock $k$ (single investment) with confidence coefficient $(1-\alpha) 100 \%$ is

$$
\operatorname{VaR}_{k}(\alpha)=-S_{0}\left(\hat{\mu}_{k}+Z(\alpha) \hat{\sigma}_{k}\right)
$$

where $S_{0}$ is the initial investment, $\hat{\mu}_{k}$ and $\hat{\sigma}_{k}$ are the mean and standard deviations of stock return $k$, respectively, and $Z(\alpha)$ shows the inverse of the logistic distribution value $Z$, that is $Z(\alpha)=\ln \left(\frac{\alpha}{1-\alpha}\right)$.

$\mathrm{VaR}$ estimation for portfolio investment is

$$
\operatorname{VaR}_{p}(\alpha)=-S_{0}\left(\hat{\mu}_{p}+Z(\alpha) \hat{\sigma}_{p}\right)
$$

where $S_{0}$ is the initial investment, $\hat{\mu}_{p}$ and $\hat{\sigma}_{p}$ are the mean and standard deviations of portfolio, respectively (Dowd, 2002; Sukono et al., 2019).

\subsection{VaR Estimation with Historical Simulation Method}

VaR estimation using historical simulation method is a nonparametric VaR estimation, without assuming the return distribution is part of the parametric family distribution (Ruppert, 2004: 346; Sukono et al., 2019).

Estimating VaR with the historical simulation method, returns are ordered from the largest to the smallest, then quantile each data is sought to obtain a return value that is close to confidence coefficient $(1-\alpha) 100 \%$. So we get the VaR estimate for stock $k$ (single investment) is

$$
\operatorname{VaR}_{k}(\alpha)=-S_{0} \cdot \text { quantile }_{k} \text {. }
$$

VaR estimation for portfolio investment is

$$
\operatorname{VaR}_{k}(\alpha)=-S_{0} \cdot \text { quantile }_{p} .
$$

\subsection{Backtest}

After getting the results of $\mathrm{VaR}$ estimation, a validity test (backtest) is performed on the VaR model used. In this paper, a backtest is conducted to test the consistency of the VaR method for the actual loss incurred and in its calculation the Lopez II approach is used which states the size of the loss function as follows 


$$
C_{i}= \begin{cases}1+\left(L_{i}-V a R\right)^{2}, & L_{i}>\operatorname{VaR} \\ 0, & L_{i} \leq \operatorname{VaR}\end{cases}
$$

where $L_{i}$ is the daily return. After getting the loss function, the QPS (Quadratic Probability Score) is calculated as follows

$$
Q P S=\frac{2}{n} \sum_{i=1}^{n}\left(C_{i}-p\right)^{2}
$$

Where $p$ is the value of $\alpha$ of the confidence coefficient of $(1-\alpha) 100 \%$. For QPS values, the smaller the VaR model, the better (Dowd, 2002; Sukono et al., 2019).

\section{Results and Discussion}

\subsection{Calculation of Return for a Single Investment and Portfolio}

Share data used in this paper are shares of BNI, BRI and portfolio. The portfolio formed, weighs 0.5 BNI and 0.5 BRI shares. Using equations (1) and (2), a single investment return and portfolio can be calculated.

\subsection{VaR and Backtest Analysis}

After the VaR and backtest estimation steps, the following will be analyzed the VaR and backtest estimation results for both single and portfolio investments.

\subsubsection{VaR and Backtest Analysis for a Single Investment}

Based on the results of the backtest that has been obtained, the greater the confidence coefficient will result in a smaller QPS. Therefore, for the biggest confidence coefficient, which is $99.9 \%$, in BNI shares, the smallest QPS is obtained by the historical simulation method. Whereas for BRI's shares, the smallest QPS was obtained using the normal distribution approach. This shows that the most consistent or best method used to estimate VaR on BNI and BRI shares sequentially is the historical simulation method and the normal distribution approach.

Then based on the results of the analysis will be applied to the following example. Suppose an investor wants to invest their capital in BNI and BRI with an initial investment of 10,000,000.00 IDR and a confidence coefficient of $99.9 \%$, then based on the results of the previous VaR estimation, obtained $\mathrm{VaR}$ with the best method as follows

$$
\begin{gathered}
\text { BNI } V a R=10,000,000.00 \times 0.1175400=1,175,400.00 \mathrm{IDR}, \\
\text { BRI } V a R=10,000,000.00 \times 0.0631635=631,635.00 \mathrm{IDR}
\end{gathered}
$$

From these results, it can be seen that BRI VaR yields a smaller value than BNI VaR. In other words, investing in BRI shares will have a smaller risk of loss than investing in BNI shares. So, with an investment of 10,000,000.00 IDR in BRI shares and a $99.9 \%$ confidence coefficient, the investor will risk a loss of 631,635.00 IDR.

\subsubsection{VaR and Backtest Analysis for Portfolio Investment}

Similar to the results of the backtest for a single investment before, namely for the greater the confidence coefficient will result in a smaller QPS. Therefore, for the biggest confidence coefficient, which is $99.9 \%$, in portfolio 5, the smallest QPS is obtained by the historical simulation method. This shows that the most consistent or best method used to estimate VaR in portfolio 5 is the historical simulation method (Sulaiman, 2003). 
Then based on the results of the analysis will be applied to the following example. Suppose an investor wants to invest their capital in portfolio 5 with an initial investment of 10,000,000.00 IDR and a confidence coefficient of $99.9 \%$, then based on the results of the previous VaR estimate, obtained portfolio VaR 5 with the best method as follow

$$
\text { Portfolio } 5 \text { VaR }=10,000,000 \times 0,0776643 \text { IDR }=766,643.00 \mathrm{IDR} \text {. }
$$

So, with an investment of $10,000,000.00$ IDR in portfolio 5 and a $99.9 \%$ confidence coefficient, the investor will risk a loss of 776,643.00 IDR.

Furthermore, from the overall $\mathrm{VaR}$ estimation results for both single and portfolio investments, investing in a portfolio will be more profitable or have less risk than investing singly. This is because the standard deviation of portfolio returns is smaller than the standard deviation of returns on a single investment, which in turn will reduce $\mathrm{VaR}$.

\section{Conclussion}

The results of the validity test (backtest) of the three $\mathrm{VaR}$ methods show that the best method used in estimating $\mathrm{VaR}$, in this case, is the historical simulation method for BNI shares and portfolios, as well as the normal distribution approach method for BRI shares. Based on the VaR estimation results using the best method, the risk of investment loss in BRI shares is less than the investment in BNI shares. So investing in BRI will be more profitable than investing in BNI. Portfolio investment has a smaller risk value than a single investment, so that in order to minimize losses in investing it is better to diversify investments by forming a portfolio.

\section{References}

Dowd, K. 2002. An Introduction to Market Risk Measurement. Chichester, New York: John Wiley \& Sons.

Dudewicz, E. J., and Mishra, S. N. 1988. Modern Mathematical Statistics. Singapore: John Wiley \& Sons.

Hogg, R. V. and Craig, T. A. 1995. Introduction to Mathematical Statistics, Fourth Edition. New Jersey: Prentice Hall.

Husnan, S. 1994. Dasar-Dasar Teori Portofolio dan Analisis Sekuritas, Edisi 3. Yogyakarta: Unit Penerbit dan Percetakan AMP YKPN.

Marrison, C. 2002. The Fundamental of Risk Measurement. New York: McGraw Hill Book Company.

Mood, A. M., Graybill, F. A. and Boes, D. C. 1963. Introduction to the Theory of Statistics, Third Edition. New York: McGraw Hill Book Company.

Redhead, K. 1997. Financial Derivatives: An Introduction to Future, Forwards, Options and Swaps. Prentice Hall Europe.

Ruppert, D. 2004. Statistics and Finance an Introduction. New York: Springer.

Sukono, Subartini, B., Napitupulu, H., Hidayat, Y., Putra, A.S., and Bon, A.T. 2019. Value-at-Risk and Modified Value-at-Risk under Asset Liability by Using Time Series Approach. Proceedings of the International Conference on Industrial Engineering and Operations Management, Bangkok, Thailand, March 5-7, 2019, 2106-2117. 
Sulaiman, W. 2003. Statistik Nonparametrik, Contoh Kasus dan Pemecahannya dengan SPSS. Yogyakarta: Andi.

Walpole, R. E. and Myers, R. H. 1978. Ilmu Peluang dan Statistika untuk Insinyur dan Ilmuwan. Terjemahan oleh R. K. Sembiring. 1986. Bandung: Institut Teknologi Bandung. 